\title{
LA SEGUNDA DESCENTRALIZACIÓN
}

(Documento hecho público por el Partido Popular el 20 de febrero de 2002) 



\section{LA SEGUNDA DESCENTRALIZACIÓN}

(Documento hecho público por el Partido Popular

el 20 de febrero de 2002)

El 20 de febrero de 2002, el Partido Popular presentó un documento en el que se recogen sus propuestas más importantes para dar un nuevo paso en la descentralización territorial española, con la idea de llevar a cabo un traspaso de competencias desde la Comunidades Autónomas hacia los Municipios. Al día siguiente, el primer partido de la oposición hizo público un documento de respuesta, en el que recoge sus propias iniciativas y comenta las que habian sido planteadas por el PP. Recogemos a continuación ambos documentos, que suponemos serán un punto de referencia en el debate político de los próximos meses, en el marco del llamado "Pacto Local».

La construcción del Estado de las Autonomias, iniciada con la aprobación de la Constitución de 1978, está alcanzando su madurez en la actualidad. Una vez realizados la mayor parte de los traspasos de competencias previstos en los Estatutos, y establecido un sistema de financiación estable basado en los principios de autonomía, suficiencia y solidaridad, se está culminando un proceso de descentralización política y administrativa que por su intensidad y rapidez no tiene parangón en los países de nuestro entorno.

El modelo de organización territorial contenido en nuestra Constitución se ha revelado como la fórmula más adecuada para dar respuesta a las demandas de autogobierno históricamente planteadas en España. La consolidación del Estado autonómico se está consiguiendo gracias a la búsqueda de un consenso básico permanente entre las principales fuerzas políticas nacionales. La mejor expresión de este compromiso político fueron los Acuerdos Autonómicos de 28 de febrero de 1992 y la posterior aprobación de las reformas de los Estatutos 
de todas las Comunidades que utilizaron la vía de acceso a la autonomía del artículo 143 de la CE. En el Partido Popular consideramos que esta voluntad de acuerdo debe seguir presidiendo la actuación de todas las fuerzas políticas en las materias relacionadas con la organización territorial del Estado; esta es la razón que nos mueve a elaborar esta propuesta.

Si bien el esquema de organización política y administrativa de nuestro país responde hoy a una realidad fuertemente descentralizada, este proceso de transferencia de competencias desde el Estado hacia las Comunidades Autónomas no ha tenido un reflejo equivalente en el siguiente escalón territorial: la Administración Local. Durante todos estos años los Entes Locales han visto prácticamente inalterada la configuración legal de su ámbito competencial, sin que se haya producido una continuación del proceso descentralizador en favor de estas Administraciones que son las más próximas a los ciudadanos.

Por todo ello, el Partido Popular considera que este es el momento adecuado para dar un nuevo impulso al proceso descentralizador, ahora en favor de los Entes Locales. De esta forma queremos dar respuesta a la demanda mayoritariamente planteada por los municipios y provincias en el Acuerdo aprobado por unanimidad en la Comisión Ejecutiva de la Federación Española de Municipios y Provincias, el 24 de septiembre de 1996, con la denominación de «Bases para el Pacto Local» y, lo que es más importante, queremos profundizar en el desarrollo de nuestro modelo de organización territorial.

Impulsar la atribución de nuevas competencias a los Entes Locales supone dar un mejor cumplimiento de los principios que inspiran la Constitución española. El Título VIII no admite que ninguna de las Administraciones que integran el edificio institucional permanezca en una posición secundaria, postergada con respecto a las demás. Igualmente, este esfuerzo descentralizador se fundamenta en lo establecido en el artículo 4 de la Carta Europea de Autonomía Local ratificada por España el 20 de enero de 1988 y, especialmente, de su apartado 3 , en el que se recomienda encomendar el ejercicio de las competencias públicas a las autoridades más cercanas a los ciudadanos.

Deben ser ahora las Comunidades Autónomas las que recojan el testigo para seguir avanzando en la descentralización, procurando así la mejor asignación de las responsabilidades políticas y una mejor gestión de las políticas públicas. Para hacerlo posible, han de atribuir parte de sus competencias a los Entes Locales que integran sus territorios, cediendo para ello los medios humanos, materiales y presu- 
puestarios que hagan posible una gestión adecuada. Nuestro objetivo último es el de mejorar la calidad de vida de los ciudadanos procurando una prestación más eficiente de los servicios públicos.

No obstante, el modo por el cual se lleve a cabo esa descentralización debe atender a la evidente diversidad - histórica, institucional y geográfica - de nuestras nacionalidades y regiones, así como a la distinta estructura local existente en cada una de ellas. En consecuencia, es necesario abordar este proceso de una manera flexible, adaptándose a la realidad de cada territorio y respetando los acuerdos que puedan alcanzarse entre los gobiernos de cada una de las Comunidades Autónomas y sus respectivos Entes Locales.

En consecuencia,

TENIENDO EN CUENTA que:

a) El artículo 137 de la Constitución garantiza la autonomía local, pero no establece un listado concreto de materias sobre las que las Entidades Locales hayan de ejercer competencias, remitiendo así al legislador ordinario su determinación en los distintos ámbitos de la acción pública.

b) A la hora de atribuir competencias a los Entes Locales el legislador estatal no puede disponer de las que la Constitución y los Estatutos de Autonomia han ido atribuyendo a las Comunidades Autónomas.

c) En esta segunda descentralización es esencial alcanzar la concertación de voluntades entre cada una de las Comunidades Autónomas y los Entes Locales de sus respectivos territorios, con el objeto de lograr el deseable y necesario consenso en un asunto de capital importancia para la articulación territorial del Estado.

d) Las Comunidades Autónomas no tienen límites jurídicoconstitucionales para atribuir nuevas competencias ejecutivas a los Entes Locales en materias de su titularidad.

e) Los criterios de eficiencia deben presidir la atribución de competencias a unos u otros niveles de la Administración. El mejor servicio a los ciudadanos debe guiar, también en esta nueva etapa, el proceso descentralizador.

Por todo lo expuesto, el Partido Popular PROPONE:

1. Impulsar en el ámbito de cada una de las Comunidades Autónomas el desarrollo de pactos locales con objeto de atribuir nuevas competencias a los municipios, las provincias y otros Entes Locales. 
2. Las materias que podrán ser objeto de descentralización son las recogidas en el Acuerdo aprobado por la FEMP el 24 de septiembre de 1996 con la denominación de "Bases para el Pacto Local». Los Pactos Locales Autonómicos contemplarán algunas áreas de las competencias actualmente desarrolladas por las Comunidades Autónomas en: Consumo, Deportes, Educación, Empleo, Juventud, Medio Ambiente, Mujer, Ordenación del Territorio y Urbanismo, Patrimonio Histórico-Artístico, Protección Civil, Sanidad, Servicios Sociales, Transporte, Turismo y Vivienda.

3. Una Ley aprobada por la Asamblea Legislativa de cada una de las Comunidades Autónomas será el instrumento normativo a través del cual se concretarán los cauces que permitan llevar a cabo este proceso. En ella deberán determinarse las materias, procedimientos y vías de participación de las Entidades locales correspondientes.

4. La cesión de competencias en favor de los Entes locales, que tendrá siempre carácter voluntario para éstos, deberá instrumentarse a través de alguno de los siguientes mecanismos jurídicos:

a) La atribución legislativa de la competencia al Ente local correspondiente, sin perjuicio de la superior potestad normativa y planificadora de la Comunidad Autónoma. Siempre que ello fuera posible, ésta deberia ser la modalidad utilizada.

b) La delegación de competencias en aquellas materias en las que los controles de oportunidad sean especialmente relevantes para una adecuada prestación de los servicios.

c) La encomienda de gestión cuando resulte ser el método más eficaz para la realización de actividades de carácter material, técnico o de servicios.

d) El establecimiento y desarrollo de mecanismos adecuados de cooperación (convenios y conciertos), especialmente cuando se trate de la prestación de servicios compartidos o complementarios entre varias Administraciones.

1. Cada Asamblea legislativa deberá decidir, atendiendo a las características propias de su territorio, $y$ a partir de los acuerdos alcanzados con los representantes de los Entes locales de su Comunidad, cuál de los mecanismos jurídicos anteriores es más adecuado para llevar a cabo el proceso en cada caso.

2. El esquema de descentralización resultante deberá dar a las Entidades Locales un margen suficiente para el establecimiento de políticas propias, sin perjuicio de las competencias de planificación, 
ordenación y coordinación generales, que seguirán siendo ejercidas por las Comunidades Autónomas.

3. En principio, los municipios serán los destinatarios preferentes de las competencias transferidas o delegadas. En todo caso será esencial tomar en consideración su capacidad de gestión, garantizando en todo momento la adecuada prestación de los servicios públicos.

4. Se considera esencial el papel que han de desempeñar las Diputaciones Provinciales, Cabildos y Consells insulares como entidades de apoyo a los municipios medianos y pequeños para garantizar una correcta prestación de los servicios que éstos tengan encomendados.

5. Asimismo se considerará la posibilidad de fomentar, especialmente en las zonas rurales donde existan núcleos de población muy pequeños, la previa constitución de entidades asociativas de municipios en áreas que sean geográfica y socioeconómicamente coherentes para la asunción de las nuevas competencias. En tal caso, las diversas entidades locales con base asociativa que se constituyan deberán asumir un paquete competencial mínimo idéntico a efectos de garantizar la necesaria coherencia de la puesta en práctica de las políticas públicas, y sin perjuicio de que pudiesen añadir al mismo otras competencias.

6. En la medida de lo posible, este proceso irá acompañado del establecimiento de indicadores que permitan la medición de la eficacia en la gestión de los servicios públicos descentralizados en favor de los Entes Locales, de tal modo que se puedan valorar de modo riguroso las consecuencias favorables o desfavorables que la atribución de la competencia haya podido generar.

7. Resulta especialmente importante la identificación y valoración de la financiación necesaria para la prestación de los servicios. Esta financiación deberá proceder de las Comunidades Autónomas ya que éstas, a través de los procesos de traspaso, han recibido de la Administración General del Estado los recursos necesarios para la prestación de los servicios públicos que ahora se van a descentralizar.

8. La evaluación financiera se realizará atendiendo, al menos, los siguientes aspectos:

Valoración del coste efectivo del servicio prestado por la Comunidad Autónoma que atribuye la competencia. 
Previsión de la evolución futura del gasto, para mantener en el tiempo una prestación adecuada del servicio público que se descentraliza.

1. El Partido Popular se compromete a presentar en las Asambleas Legislativas de cada una de las Comunidades Autónomas las proposiciones o proyectos de leyes reguladores de este proceso descentralizador de competencias en favor de los Entes Locales, 0 adaptar sus normas vigentes en materia de régimen local en este sentido.

2. El Partido Popular oferta esta propuesta a todas las fuerzas políticas con representación parlamentaria, al objeto de que se convierta en acuerdo. El consenso entre las fuerzas políticas debe ser, una vez más, el que presida este decisivo paso hacia delante en la consolidación del proceso descentralizador que se ha llevado a cabo en nuestro país en los últimos 23 años.

Madrid, 20 de febrero de 2002. 